\title{
GENERATED VOLTAGE CONTROL IN A SWITCHED RELUCTANCE MOTOR/GENERATOR
}

\author{
A. W. F. V. Silveira, D. A. Andrade, A. Fleury*, L. C. Gomes, C. A. Bissochi Jr, H. de Paula** \\ Laboratório de Acionamentos Elétricos da Universidade Federal de Uberlândia \\ Uberlândia - MG, Brasil \\ *Pontifícia Universidade Católica de Goiás / Universidade Estadual de Goiás, **Universidade Federal de Minas Gerais \\ augusto.ufu@gmail.com, darizon@ufu.br
}

\begin{abstract}
This paper reports on the switched reluctance machine operating as motor/generator (SRM/G) excited through an external power source. The half-bridge static converter topology is used to drive the machine in either modes of operation. Transition from motor to generator mode is firstly discussed and results from both simulation and experimental tests are included. Operating as generator, the output generated voltage is a function of the phase magnetization level during excitation; therefore, by controlling the phase excitation level, the output voltage is also controlled. Three output voltage control techniques are proposed and analyzed: 1- Variable Angle (VA), effected by controlling the phases turning off angles with a fixed DC link excitation voltage; 2 - Chopping (CH), attained by chopping the DC link supply during the phases magnetization while keeping a fixed conduction period; and 3 - Variable Link (VL), reached by controlling the DC link excitation voltage by means of a DC-DC buck converter in a fixed conduction period. For the experimental work, full digital control is implemented. Results obtained with the implementation of the output voltage control techniques are presented. Relative performance comparison is included, showing that the CH followed by VL strategy brings the best outcome.
\end{abstract}

Keywords - Digital Control, Generator Load Voltage Control, SRM, Switched Reluctance Motor/Generator.

\section{INTRODUCTION}

Combined motor/generator electric devices have been developed in recent years to fill industrial needs. They are expected as a novel embedded technology to substitute both the engine starter and the alternator. Automobiles [1-4] and aircrafts [5] are potential applications. Replacing the starter and the generator for just one electrical machine can reduce global manufacturing costs and also increase the engine performance and reliability [6]. The solution sounds attractive and competitive since this technology also allows the use of stop and go strategies in the automotive industry. As it is known, these strategies avoid the engine working at idle state, improving the vehicle autonomy and reducing the air pollution. Moreover, the starter/generator system can be designed to increase the electrical system voltage so as to reduce electrical current requirements to supply the crescent demand of power due to new loads embedded in modern

Manuscript received on 15/05/2010. Revised on 13/07/2010. Accepted for publication on $22 / 08 / 2010$ by recommendation of the Editor João Onofre P. Pinto. vehicles. It is to point out that many studies suggest that the voltage of the electrical system in cars should increase from $12 \mathrm{~V}$ DC to $42 \mathrm{~V}$ DC [1-3].

Whenever a new driving application comes about, a natural question that emerges is the definition of which of the available types of electric machines provides the best overall characteristics to attend that application. It has not been different with motor/generator (MG) proposals, which require operation in a wide speed range, high torque per volume capability, ruggedness, high efficiency, low maintenance and operation in harsh environments [4].

Different types of electrical machines have been considered to attend MG applications, including induction, permanent magnet synchronous and switched reluctance machines [6-8]. The outcome of these studies is that the switched reluctance machine is a potential candidate, given the inherent features that enhance its competitiveness as MG. It is robust, has a low cost of production, presents small rotor inertia, it's easy to control, operates under variable speed conditions, is high temperature tolerant and behaves well under fault of phase situation. Its windings are fully concentrated in the stator poles and there are no windings in the rotor (cool rotor), which allows safety for very high operational speeds and operation in harsh conditions $[4,8]$.

Concerning generation, as traditional synchronous and induction generators, switched reluctance machines can generate electrical energy either in self-excitation or external excitation modes. SRMs do not have intrinsic self-excitation capability, but they can work in this condition after being provided with excitation requirements during starting. An auxiliary external battery or small permanent magnets conveniently inserted in the stator poles [9] can be used for the purpose of offering initial conditions for generated voltage built-up. As the generated voltage is normally fed to a DC link capacitor, once this capacitor is charged, it can provide excitation energy through a power controller, leading to full self-excitation operation. Recent studies have also shown the SRM working as autonomous generators [10-12]. Although switched reluctance generators have been primarily studied for automotive and aerospace systems $[3,5]$, recent trends show the possibility of its use in other variable speed constant frequency (VSCF) applications, such as wind power systems [13-14]. A situation which often arises is a comparison of performance and efficiency of SRGs with induction generators based systems. In favor of SRGs, the following quotes are made: SRGs can be used in direct-drive systems eliminating gearboxes, have a more convenient constructive structure with independent stator phases, demand simpler electronic converter topologies (and therefore are easier to control) and require less maintenance 
[6-8]. Another recent application is the use of SRMs for storage of mechanical energy in flywheels [15].

In this paper, switched reluctance motor/generator operation with external excitation by means of an electric power source is focused. It presents a study of the SRM driven by a half-bridge converter (HB), modified to allow the switching between the motor and generator operation modes. Three strategies are proposed to control the output generated voltage applied to the load. Simulations and experimental results are included and show the SRM/G operation during the transition between motor and generator, as well as the SRG operating in closed-loop load voltage control. A comparative analysis between the behavior and relative efficiency of the different strategies is included.

\section{THE SWITCHED RELUCTANCE MACHINE}

Figure 1 shows some features of the modern switched reluctance machine. It has a doubly salient poles structure and the phase coils are wound only in the stator poles. Rotors are also salient and carry no electric conductors, leading to operation based on reluctance torque only [16]. Due to this construction, the stator phases self-inductances vary alternately with rotor position, ranging from a minimum to a maximum value as function of the rotor position. Operation as motor or generator is achieved just by governing the unidirectional flux of current in the windings according to the rate of change of a phase inductance with rotor position. If current flows through the winding during a positive rate of change of the inductance, motor torque is produced. On the other hand, if the current flows in the winding during the negative rate of change of its inductance, a negative torque is produced, thus characterizing generator operation. In this way, the machine generates electric power. Figure 2 shows the phase current and inductance behavior for four-quadrant SRM/G operation.

\section{A. Mathematical model}

The circuit equation of one phase can be written as

$$
v=R i+L \frac{d i}{d t}+i \omega \frac{d L}{d \theta}
$$

where $v$ is the source voltage, $i$ is the phase current, $R$ is the phase resistance, $L$ is the inductance of the phase, $\theta$ is the rotor position and $\omega=d \theta / d t$ is the speed of the rotor. The third term of the right side of the equality is the induced electromotive force $(\mathrm{emf})$.

The electromagnetic torque produced by the machine is expressed as

$$
T(\theta, i)=\frac{1}{2} i^{2} \frac{d L}{d \theta}
$$

From (2), one observes that the signal of the produced torque depends on the signal of the inductance variation in relation to the rotor position $(d L / d \theta)$.

The dynamic torque equation including the inertia $(J)$ and friction $(D)$ coefficients is

$$
T_{m}=T_{\text {emag }}-J \frac{d \omega}{d t}-D \omega
$$

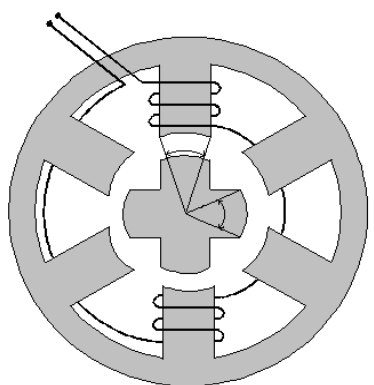

Fig.1. Cross section of a $6 / 4$ SRM/G structure.

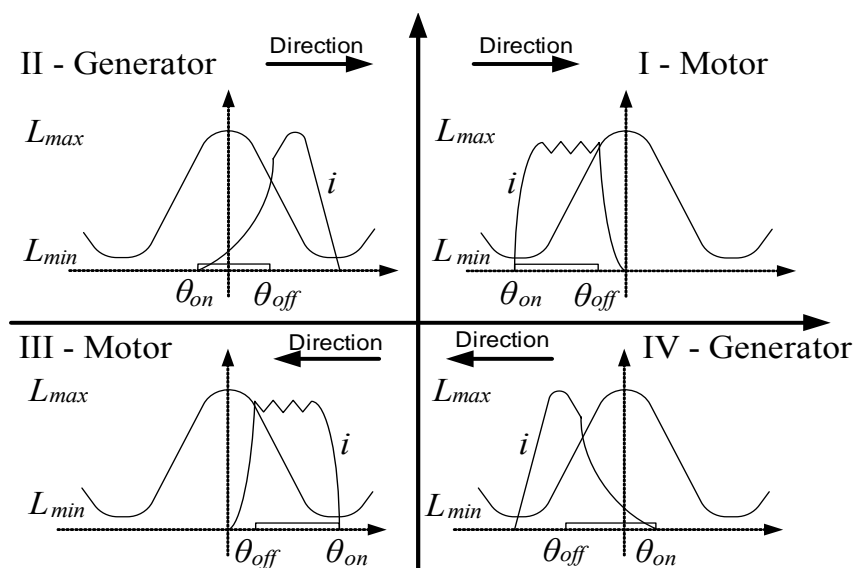

Fig.2. Phase current and inductance variation as a function of the rotor position for four-quadrant operation of the SRM/G.

In a three-phase machine with sequentially energized phases, one at a time, the resultant electromagnetic torque is given by

$$
T_{\text {emag }}=\frac{1}{2}\left(i_{a}^{2} \frac{d L_{a}}{d \theta}+i_{b}^{2} \frac{d L_{b}}{d \theta}+i_{c}^{2} \frac{d L_{c}}{d \theta}\right)
$$

From all the relations presented above, the mathematical model of the SRM is derived, given by (5). This matrix of states completely describes the dynamic behavior of the SRM.

$$
\begin{aligned}
& {\left[\begin{array}{c}
v_{a} \\
v_{b} \\
v_{c} \\
T_{m} \\
0
\end{array}\right]=\left[\begin{array}{ccccc}
R_{a} & 0 & 0 & 0 & 0 \\
0 & R_{b} & 0 & 0 & 0 \\
0 & 0 & R_{c} & 0 & 0 \\
i_{a} r_{1} & i_{b} r_{2} & i_{c} r_{3} & -D & 0 \\
0 & 0 & 0 & -1 & 0
\end{array}\right]\left[\begin{array}{c}
i_{a} \\
i_{b} \\
i_{c} \\
\omega \\
\theta
\end{array}\right]+} \\
& +\left[\begin{array}{ccccc}
L_{a} & 0 & 0 & 0 & i_{a} \frac{d L_{a}}{d \theta} \\
0 & L_{b} & 0 & 0 & i_{b} \frac{d L_{b}}{d \theta} \\
0 & 0 & L_{c} & 0 & i_{c} \frac{d L_{c}}{d \theta} \\
0 & 0 & 0 & -J & 0 \\
0 & 0 & 0 & 0 & 1
\end{array}\right]\left[\begin{array}{c}
\cdot \\
i_{a} \\
\dot{i_{b}} \\
\dot{i_{c}} \\
\dot{\omega} \\
\dot{\theta}
\end{array}\right]
\end{aligned}
$$

where:

$$
r_{1}=\frac{1}{2} \frac{d L_{a}}{d \theta} ; r_{2}=\frac{1}{2} \frac{d L_{b}}{d \theta} ; \quad r_{3}=\frac{1}{2} \frac{d L_{c}}{d \theta}
$$




\section{B. Computational modeling}

The software Matlab/Simulink ${ }^{\circledR}$ is used to develop a nonlinear simulation of the SRM operating as a motor/generator. The simulation program accurately represents the transition of operation modes from motor to generator, which was programmed to occur when a given reference speed is reached.

To develop the computational model for the three-phase, 1 HP, 6/4 SRM prototype, experimental measurements of the linkage flux $(\lambda)$ were done for many rotor positions $(\theta)$, also considering different current values, resulting in a large data bank of the function $\lambda(\theta, i)$. Using this data, polynomial interpolation is employed to evaluate the inductance of a phase as a function of its current and the instantaneous rotor position; in this way, the effects of the saturation are considered in the simulation results. Figure 3 depicts the phase inductance obtained from the polynomial equation for $L(\theta, i)$, while Figure 4 shows a picture of the machine prototype [17].

The converter used to drive the $\mathrm{SRM} / \mathrm{G}$ is a half-bridge, commonly used to drive this type of machine. Figure 5 shows the topology of the converter used, showing the path created to deliver the energy generated for a resistive load $(Z)$, when the machine is operating as generator. This energy, in automotive applications, could be used to recharge the battery (dispensing the use of the switch), and/or to supply electro-electronic equipment. A capacitor $(C)$ is used to filter the generated pulsed voltage.

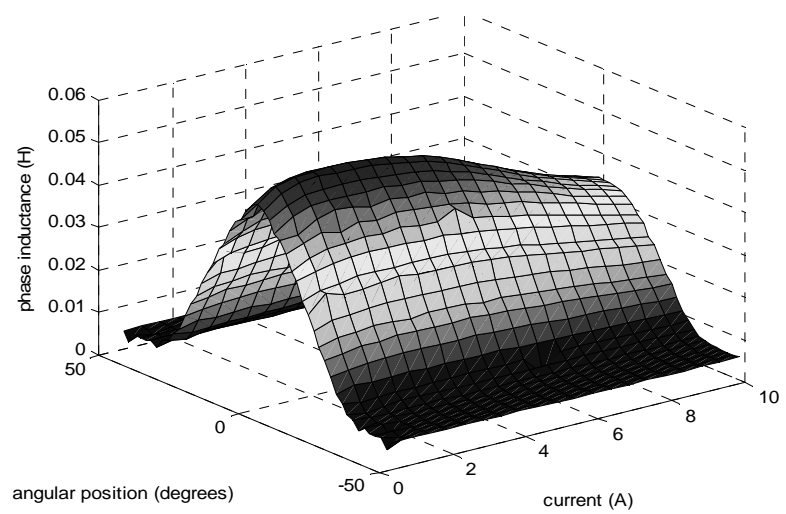

Fig. 3. Winding inductance obtained experimentally as function of the phase current and the rotor angular position.

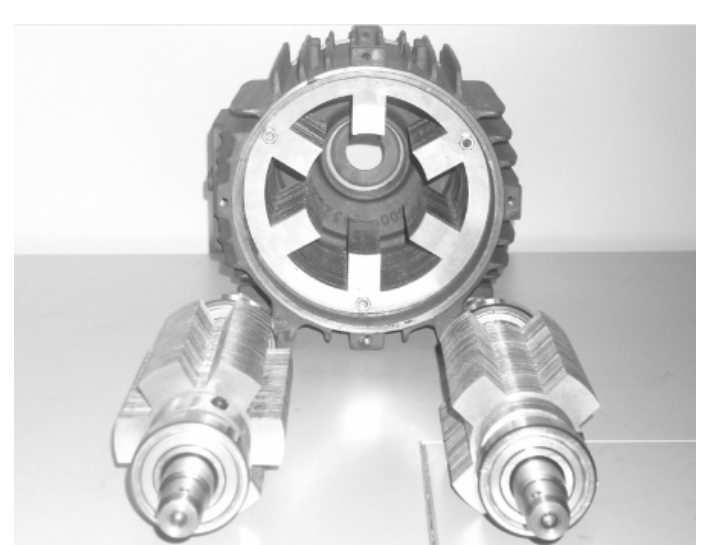

Fig. 4. The SRM prototype used in the modeling and experimental setup.

\section{CONTROL OF THE SRM/G}

\section{A. Control of the motor operation and the transition time}

In the case of motor operation, the phase is energized during the positive rate of the inductance variation with rotor position. In this mode, the error between reference and rotor actual speed is positive. When the error reaches values close to zero or negative ones, the control strategy changes the operation for generation mode. In this condition, the phase switching control is activated during the negative rate of the inductance variation and the machine converts mechanical to electrical energy. Either a combination of rotor position sensors or a computational routine to estimate the rate of change of the inductance with the rotor position [18] can be used to implement the algorithm for the phases conduction angles determination $\left(\theta_{\text {cond }}=\theta_{\text {off }}-\theta_{\text {onf }}\right)$.

In order to complete the process of changing the machine operation mode, the control strategy has to switch the relay added to the half-bridge converter, thus enabling the power generated to be delivered to the load.

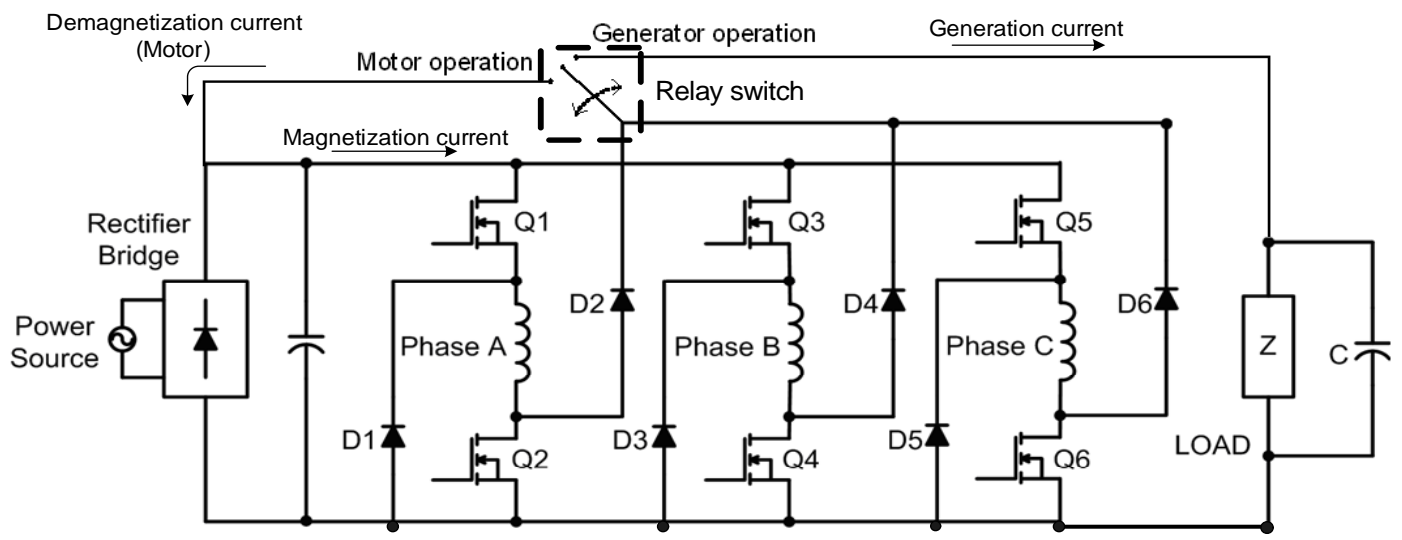

Fig. 5. Asymmetrical half-bridge converter for the SRM/G. 
A simulation of the SRM operating as a motor/generator was performed for analysis. Figure 6.a shows the rotor speed during the complete simulation time. The speed that the machine started to generate power was set to $1350 \mathrm{rpm}$, which was reached approximately at $0.25 \mathrm{~s}$ of simulated time. Once reached, this speed is deliberately kept constant. The behavior of a phase current, electromagnetic torque and gate signal of the converter, during the transition, is seen in Figure 6.b. It is observed that the current has a large peak at the beginning of the operation as generator, due to the current inrush of the discharged capacitor used to filter the voltage delivered to the resistive load $(10 \Omega)$. In order to prevent any damage of the converter switches due to this transient current, a strategy of starting the machine operation as a generator with a reduced $\theta_{\text {off }}$ can be adopted. In Figure 7 , the effect of changing the value of $\theta_{\text {off }}$ on the magnitude of the generated current is illustrated.

The voltage applied to the resistive load during the generation is seen in Figure 8.a, while Figure 8.b presents the voltage in one of the phases. Figure 8.c depicts the curve of flux vs. current, whose behavior throughout the simulation, including the transition period, can be observed. The average electric power generated and consumed (phase excitation) by the SRM/G is shown in Figure 8.d.

The generation cycle for one phase starts with the phase magnetization, when electric power $\left(P_{i n}\right)$ is drained from the source. During this stage, the electronic converter switches are on, and the rotor poles are moving towards full alignment with the stator ones. Some degrees after full alignment, the converter switches are turned off and the current path is deviated to the load through the phase diodes, delivering the demagnetization energy plus the energy converted from the mechanical source; the corresponding power is $P_{\text {out }}$ (which is higher than $P_{i n}$, as shown in Figure 8.d).

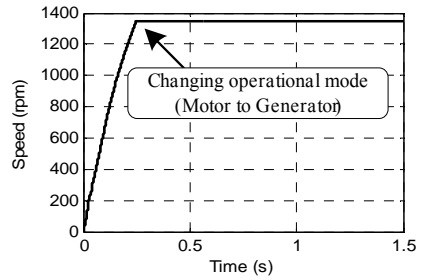

Fig. 6.a. Speed of the SRM/G.

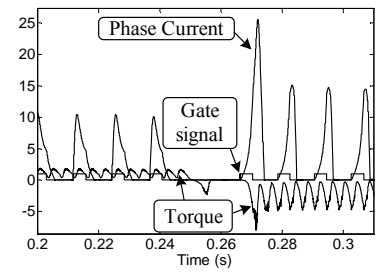

Fig. 6.b. Current of one phase and the corresponding gate signal and electromagnetic torque.

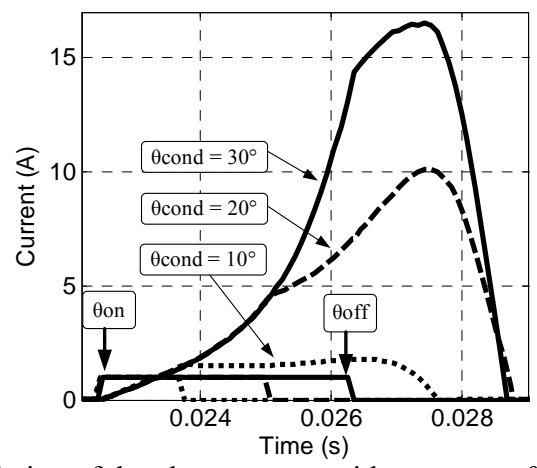

Fig.7. Variation of the phase current with respect to $\theta_{\text {off }}$ instant.
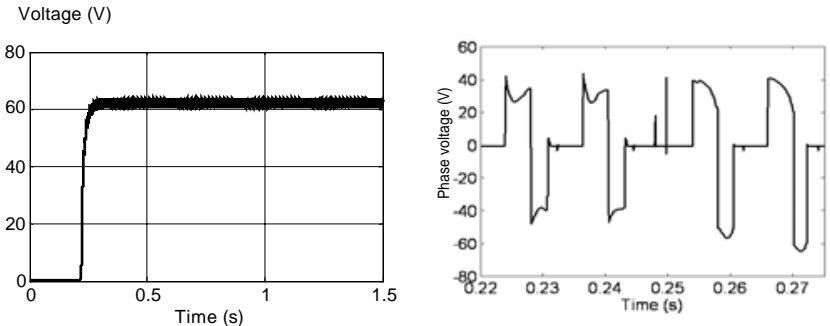

Fig. 8.a. Machine generated Fig. 8.b. Voltage in one phase. voltage.
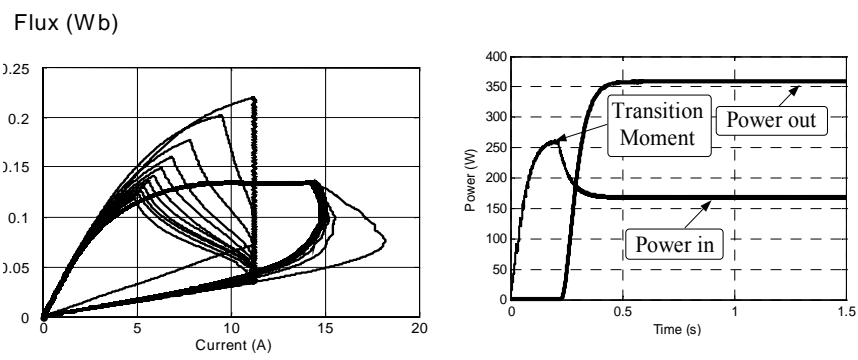

Fig 8.c. Machine flux vs. Fig. 8.d. Input and output current.

electrical power of the machine.

\section{B. Techniques for the $S R M / G$ generated voltage control}

In various industrial, automotive, aerospace and other embedded devices applications, it is required that the generated voltage have a constant value independently of the load and rotor speed. This is not possible without a control strategy able to vary the switched reluctance generator magnetization to maintain the load voltage in a fixed desired value [19].

In this paper, three alternatives for the generator magnetization control are proposed:

1 - Variation of the width of the magnetization period, such as changing the value of $\theta_{\text {off }}$ (Variable Angle - VA);

2 - Switching the voltage applied to the phases during a fixed period (fixed $\theta_{o f f}$ ), with constant DC link voltage (Chopping - CH);

3 - Control of the DC link voltage. This strategy can be implemented using a buck converter between the original DC link and the half-bridge converter (Variable Link - VL).

The three aforementioned strategies were successfully implemented both in computational simulations (using a PI controller) and experimentally (using a DSP). With regard to the simulations, the transition from motor to generator was set to occur when the SRM/G reaches $1350 \mathrm{rpm}$, with $42 \mathrm{~V}$ in the DC link and $42 \mathrm{~V}$ in the load voltage controller reference $\left(V_{\text {ref }}\right)$.

The strategy based on the variation of the magnetization period using a PI controller to regulate $\theta_{\text {off }}$ can be represented by the block diagram shown in Figure 9. The control actuates on $\theta_{\text {off }}$ to keep the generated voltage value close to the reference. It is worthy to emphasize that this variation occurs in the same fashion in the other phases of the machine, since the PI controller changes the value of $\theta_{\text {off }}$ for all the (three) phases. 
Figure 10.a shows the behavior of the generated voltage applied to the load, with the control strategy described above; as observed, the reference value $(42 \mathrm{~V})$ was properly tracked.

When simulation time reached $3 \mathrm{~s}$, the load resistance was reduced from 20 to $15 \Omega$, returning to the former value at $6 \mathrm{~s}$. This test demonstrated that the control is able to accurately keep the generated voltage around the reference value even during load transients. For this same situation, Figure 10.b exhibits the current in one of the phases of the machine.

Similarly to the previous method, the second generated voltage control strategy for the SRM/G was simulated, based on the block diagram shown in Figure 11. In this technique, the value of $\theta_{\text {off }}$ and the DC link voltage are fixed. The output of the PI controller is then used to vary the duty cycle of a PWM signal that controls the magnetization of the machine. Since all machine phases are positioned between two controlled switches of the HB converter, it is necessary to open and close the converter upper switches (Q1, Q3, Q5 Figure 5) during the phases magnetization period, in order to vary the magnetization average voltage of the SRM/G operating as generator.

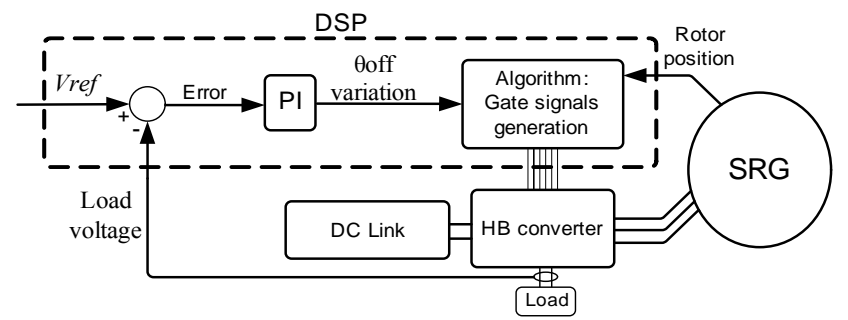

Fig. 9. Control strategy based on the variation of the magnetization period, by acting on the $\theta_{\text {off }}$ value.

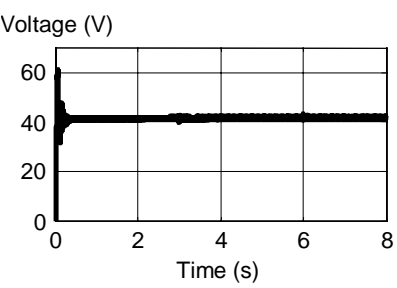

Fig. 10.a. Generated voltage applied to the load.

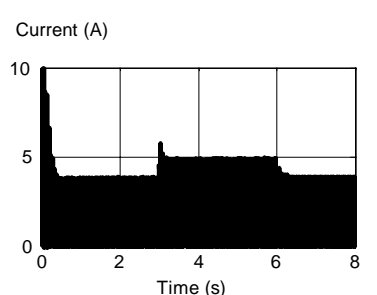

Fig. 10.b. Current in one phase of the SRM/G.
Figure 12 presents the generated voltage and the machine phase current behavior; as in the previous method, the control showed to be very effective even during the load transients.

Proceeding with the study, Figure 13 shows the block diagram that represents the third control strategy proposed in this paper. As already mentioned, this alternative is based on a PI controller used to vary the duty cycle of a PWM signal applied to a buck converter, which in turn is employed to control the supply voltage of the half-bridge converter. As in the case of the other two analyzed methods, this control scheme was able to keep the load voltage at the desired value, in both steady state and transient conditions, as illustrated by Figure 14.

The performance of the proposed voltage control techniques are now compared when the machine operates as generator under variable rotor speed. The transition from motor to generator was set to happen when the speed reaches
$130 \mathrm{rad} / \mathrm{s}$. In the simulations, the primary machine was adjusted to drive the SRM generator with sinusoidal speed oscillations, ranging from 130 to $330 \mathrm{rad} / \mathrm{s}$. As seen in Figure 15 , the three control strategies successfully maintained the voltage load around the reference value.

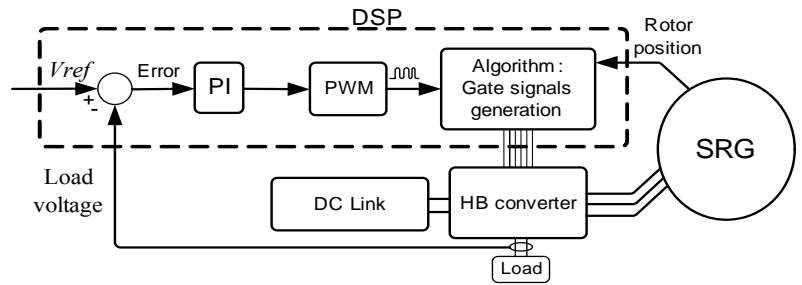

Fig. 11. Control strategy based on switching the magnetization voltage.

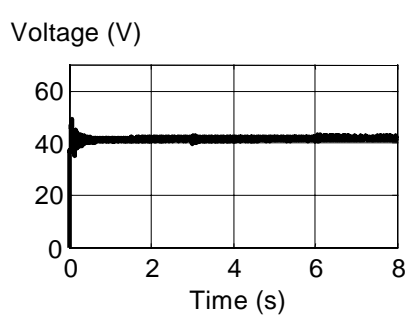

Fig. 12.a. Generated voltage for the load supply.

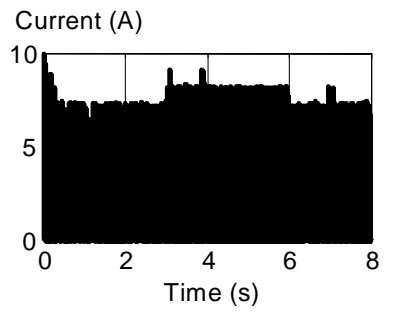

Fig. 12.b. Current in one phase of the SRM/G.

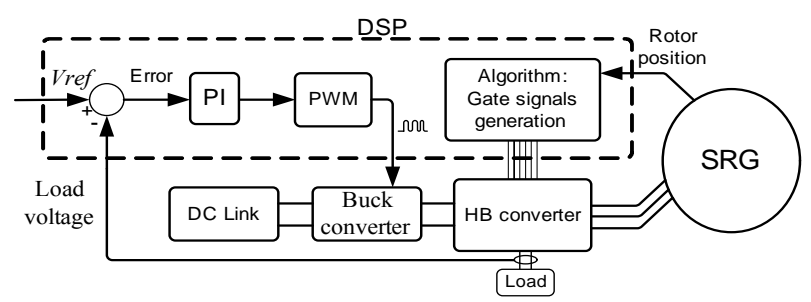

Fig. 13. Strategy based on the control of the DC link voltage.

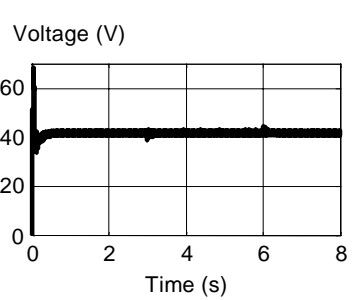

Fig. 14.a. Generated voltage applied to the load.

$$
\text { Current (A) }
$$

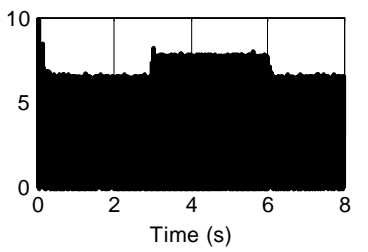

Fig. 14.b. Current in one phase of the SRM/G.

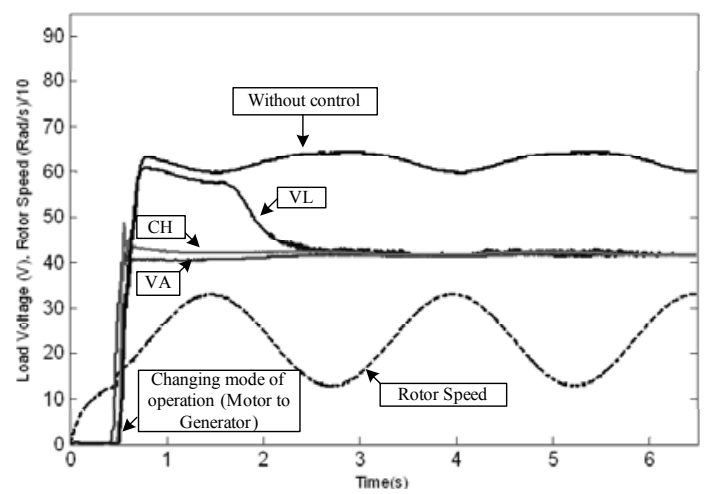

Fig. 15. Load voltage when the machine is driven with variable speed. 
Another aspect of interest is the expected overall efficiency of each strategy. Taking efficiency as the ratio of the output power $\left(P_{\text {out }}\right)$ to the load and the input power from the electrical excitation source $\left(P_{i n}\right)$ added to the input power from the mechanical source $\left(P_{m e c}=\omega T_{m e c}\right)$, this quantity is calculated as given in Table I, when the generator is driven at $1350 \mathrm{rpm}$ and supplying $20 \Omega$ of resistive load. It is seen that the VA strategy brings out the best efficiency. However, it is the one which draws more power from the excitation source. The $\mathrm{CH}$ followed by VL makes best use of the available mechanical power.

TABLE I

\begin{tabular}{lccc}
\multicolumn{4}{c}{ Strategies efficiency } \\
\hline Strategy & VA & CH & VL \\
\hline $\mathrm{P}_{\text {in }}(\mathrm{W})$ & 40.7 & 28.7 & 33.3 \\
\hline $\mathrm{P}_{\text {mec }}(\mathrm{W})$ & 59.4 & 74.0 & 73.5 \\
\hline $\mathrm{P}_{\text {out }}(\mathrm{W})$ & 86.6 & 86.3 & 87.9 \\
\hline$\eta(\%)$ & 86.4 & 83.9 & 82.3 \\
\hline
\end{tabular}

\section{EXPERIMENTAL RESULTS}

The tests were performed using the three-phase SRM prototype shown in Figure 4. The modified half-bridge converter described in section II was implemented to drive the SRM/G. A four-pole, $2 \mathrm{HP}$, three-phase induction machine driven by a vector control inverter was used as the mechanical (primary) power source. The control of the SRM/G was programmed using a TMS320F2812 fixed-point DSP. Figure 16 shows the diagram of the experimental setup, while Figure 17 presents a picture of it. In all experimental results concerning the $\mathrm{SRM} / \mathrm{G}$ phase current, $1 \mathrm{~V}$ is equivalent to $4 \mathrm{~A}$.

Figure 18 illustrates the machine phase current during the transition from motor to generator operation. Before the transition, both machines work as motors, with speed regulated by the induction motor controller. This justifies the small SRM current (and small torque). Immediately after transition, the SRM current performs an inrush profile due to the charging of the output smoothing capacitor, and settles to a more steady behavior. This effect is also observed by the exponential increase in the load voltage profile seen in Figure 19. The system can also change from generator to motor, being the results for this situation shown in Figures 20 and 21. To protect the electronic switches, a $20 \mathrm{~ms}$ dead time between transitions was set.

Figure 22 shows the built up of the voltage applied to the load (the SRG generated voltage smoothed by the capacitor) when the transition from motor to generator mode occurs. This experiment corresponds to an operation at $1350 \mathrm{rpm}$ and $25 \mathrm{~V}$ in the DC excitation link, with no voltage closed loop control. The SRG applies $54 \mathrm{~V}$ on the load; since the value of the load resistance is $20 \Omega$, a power of about $150 \mathrm{~W}$ was being delivered.

Figure 23 is a zoom of the smoothed generated voltage when the generator operates in steady state. There is a characteristic ripple, typical from this kind of machine [2021 ], whose frequency $\left(f_{\mathrm{v}}\right)$ can be calculated as

$$
f_{V}=\frac{\operatorname{Speed}[R \cdot P \cdot M] N_{S} N_{R}}{60}
$$

where $N_{S}$ and $N_{R}$ are the stator and rotor number of poles.

The voltage ripple can be minimized replacing the DC link capacitor by a bigger one, which would also increase the inrush current in the beginning of the generation mode. In order to protect the switches and prevent damages, control strategies could be used to limit the inrush current, as mentioned in section III.A.

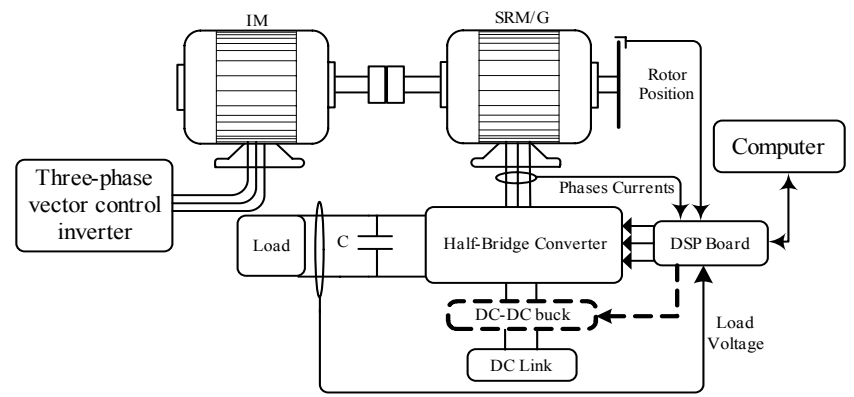

Fig. 16. Experimental setup.

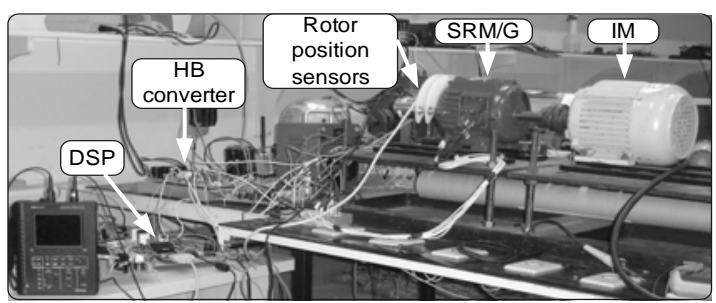

Fig. 17. Picture of the experimental setup.

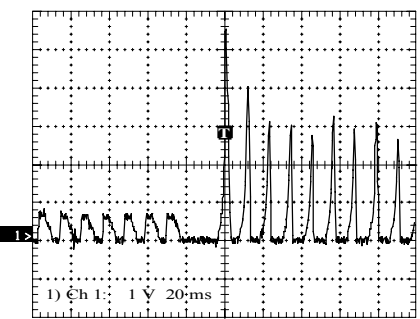

Fig. 18. Current in one of the machine phases during the transition from motor to generator mode.

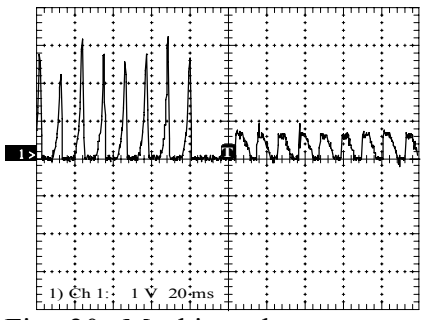

Fig. 20. Machine phase current during the generator to motor mode transition.

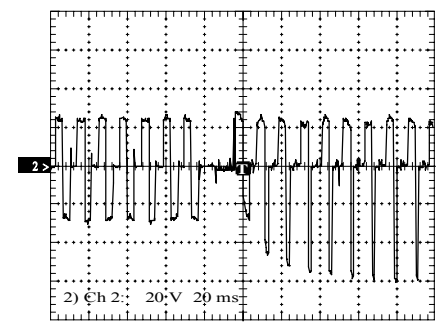

Fig. 19. Voltage in one of the phases during the motor to generator mode transition.

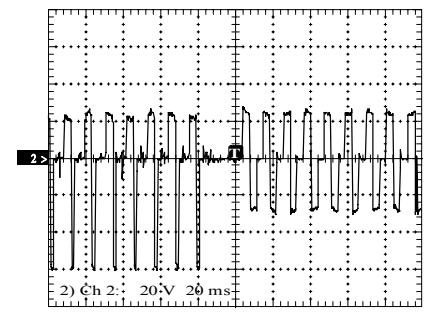

Fig. 21. Voltage in one of the phases during the generator to motor mode transition. 


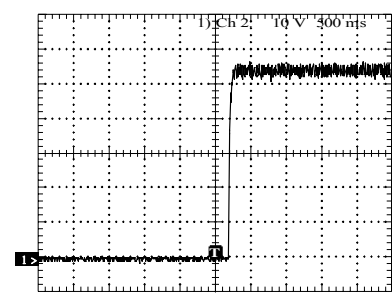

Fig. 22. Voltage applied to the load when the machine starts to generate.

\section{A. Generated Voltage Control}

The three strategies discussed in section III.B to control the generator output voltage were experimentally implemented. The PI controller used in these techniques was formulated in discrete time to be programmed into the DSP and is expressed, using the rectangular method, as

$$
U_{k+1}=K_{p} \cdot E_{k+1}+K_{p} \cdot\left(\frac{K_{i}}{K_{p}} \cdot T_{s}-1\right) \cdot E_{k}+U_{k}
$$

where $E$ is the input error between the reference and the load voltage, $U$ is the controller output, $T s$ is the sample time and $K_{p}$ and $K_{i}$ are the proportional and integral gains, respectively. Table II shows the coefficients $K_{p}$ and $K_{i}$ of the PI controllers used in the work.

\section{TABLE II}

Coefficients of the PI controllers

\begin{tabular}{ccc}
\hline Load Voltage Control Strategy & $\boldsymbol{K}_{\boldsymbol{p}}$ & $\boldsymbol{K}_{\boldsymbol{i}}$ \\
\hline $\mathrm{VA}$ & 5 & 2 \\
\hline $\mathrm{CH}$ & 2 & 0.8 \\
\hline $\mathrm{VL}$ & 0.8 & 0.3 \\
\hline
\end{tabular}

As in the simulations, the primary machine speed is kept constant at $1350 \mathrm{rpm}$. The first strategy analyzed refers to the control of $\theta_{\text {off }}$ (see Figure 9). In order to show its performance, some tests were carried out, being the corresponding results reported in the sequence. In Figure 24, the load voltage response is shown when the reference is demanded to change in a step fashion from 42 to $30 \mathrm{~V}$. The magnitude of the phase current is also illustrated during this transient. It can be noted that the load voltage follows the reference with a period of accommodation. Once the load voltage decreases and the load impedance is kept constant, the current also decreases. Figure 25 depicts another transient situation, where the voltage reference is fixed and the resistive load is instantly reduced from 20 to $15 \Omega$, increasing the demand of current. As observed, the control keeps the voltage at the set value.

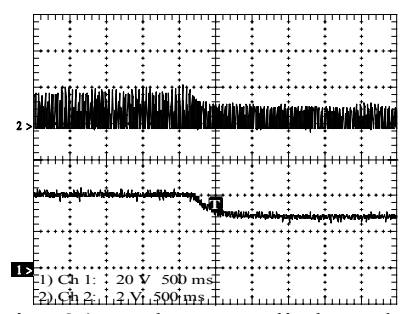

Fig. 24. Voltage applied to the load and current magnitude in one phase of the machine.

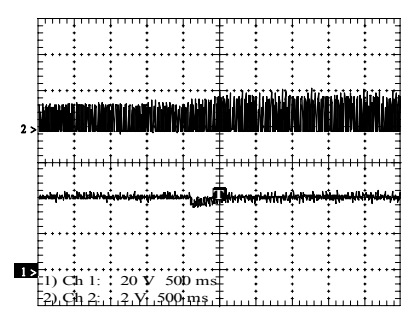

Fig. 25. Current and load voltage during a load transient.

In regard to the internal control variables, Figures 26 and 27 present the gate signal and phase current when the generator is submitted to the transient depicted in Figure 24. As it can be seen, the controller actuates reducing the magnetization period by decreasing $\theta_{\text {off }}$, which corresponds to a reduction in the phase conduction angle.

The second strategy (Figure 11), based on switching the voltage applied to the phases during a fixed conduction angle for the magnetization control, was also verified. Figure 28 shows the load voltage response when the reference drops from 42 to $30 \mathrm{~V}$ in a step. In this case, the accommodation period is shorter than that observed in the previous strategy. Figure 29 presents the curves of the machine output voltage and current when the load is reduced to $75 \%$ of its initial value ( 20 to $15 \Omega$ ), showing that the controller is able to maintain the voltage at the reference value.

Figure 30 shows the PWM controlled gate signal (see Figure 11) of the upper switch of one phase (Q1 in phase A Figure 5) and the corresponding current responsible for the phase magnetization. When Q1 and Q2 are turned off, the phase begins the demagnetization and the generation takes place in the remaining of the cycle. The upper signal in Figure 31 depicts the voltage across the phase winding over one cycle, being the continuous negative signal the generated voltage. The bottom signal corresponds to the Q1 gate signal.

The third strategy (Figure 13), using the buck converter to control the DC link excitation voltage, was experimentally tested as well. Figure 32 shows the controller performance during a step transition of the reference output voltage (42 to $30 \mathrm{~V})$ with unaltered load impedance. Once again, the controlled voltage followed the reference, as expected. Since the load resistance remains constant, the voltage and current of the load present the same behavior. The controller performance for a constant voltage reference and a reduction of $25 \%$ in the load resistance is reported in Figure 33, showing to be accurate.

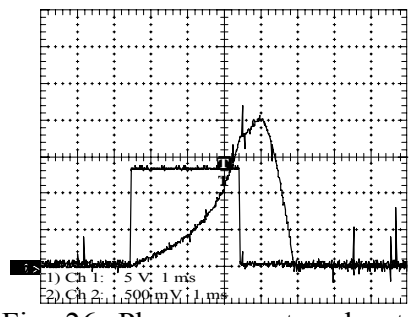

Fig. 26. Phase current and gate signal for a control reference of $42 \mathrm{~V}$.

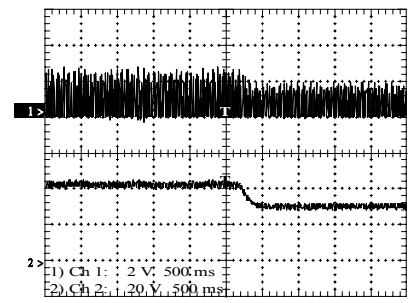

Fig. 28. Voltage on the load and current magnitude in one phase of the machine.

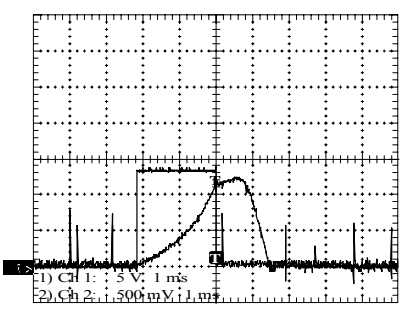

Fig. 27. Phase current and gate signal for a control reference of $30 \mathrm{~V}$.

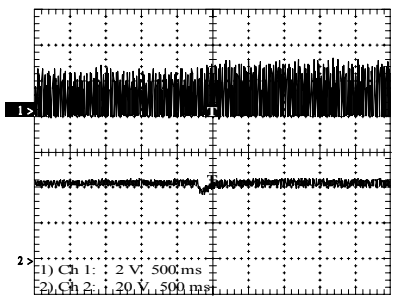

Fig. 29. Machine output current and voltage during a load transient. 


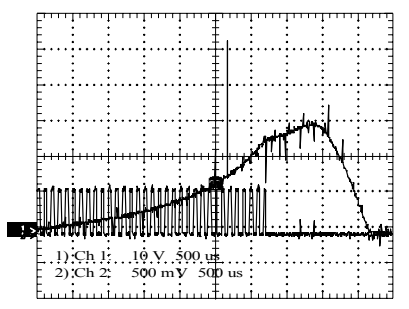

Fig. 30. PWM gate signal and phase current.

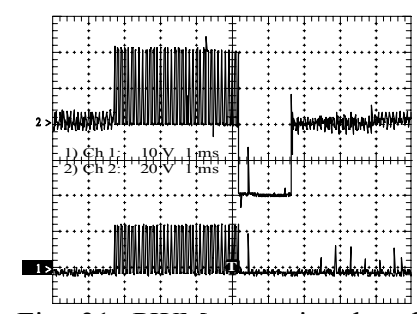

Fig. 31. PWM gate signal and phase voltage.

Figures 34 and 35 show the output of the buck converter for these two transients. When the generated voltage is demanded to reduce, the control actuates in the buck converter decreasing its voltage (Figure 34), thus reducing the DC link voltage used for the phases magnetization. When the output voltage is required to be constant and the load resistance is lowered, the control actuates increasing the excitation voltage (Figure 35). From the obtained results, it was verified that this control strategy led to the lowest load voltage ripple and the fastest transient response among the three methods analyzed in this paper.

The three methods proposed in the paper can control the load voltage with the SRM/G operating at variable speed. Figure 36 presents the curve of the load voltage and current with the machine running in the generation mode under VA strategy, with its speed increasing from $1350 \mathrm{rpm}$ to 1800 rpm. It is observed that the load voltage value was kept close to the reference $(42 \mathrm{~V})$ during the whole period of acceleration.

Once demonstrated the feasibility of the three strategies for the machine output voltage control, attention turns to their energy conversion capability. The comparative results of the generated power using each strategy is given in Figure 37 for a range of speeds. The generated power is taken as the difference between the output power delivered to the resisitive load and the electric power drawn from the DC excitation supply $\left(\mathrm{P}_{\text {out }}-\mathrm{P}_{\text {in }}\right.$ in Figure 8.d). The outcome is that the strategy using the fixed conduction angle and a chopped DC voltage to control the phase magnetization $(\mathrm{CH})$ is the one which brings the best results, followed by the method that employs the buck converter to control the excitation voltage (VL). The worst performance in terms of electromechanical conversion is observed with the technique that controls the turning off angle (VA).

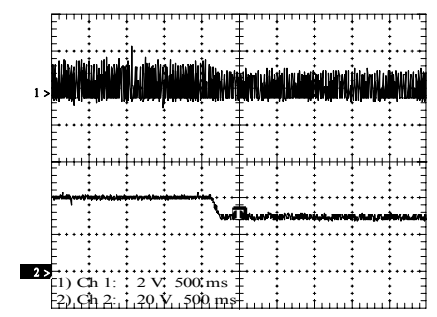

Fig. 32. Voltage on the resistive load and machine phase current magnitude.

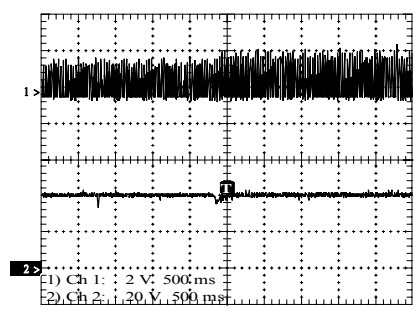

Fig. 33. Machine output current and voltage during a load transient.
Fig. 34. Load voltage during a voltage reference step transition and controlled DC link voltage.

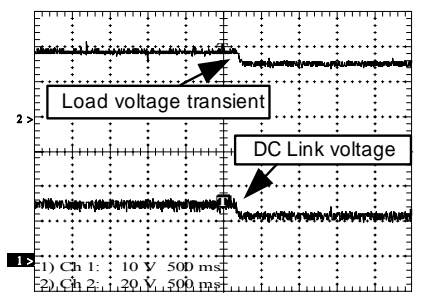

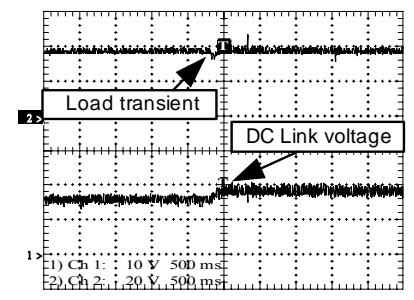

Fig. 35. Load voltage during a load transient and controlled DC link voltage.

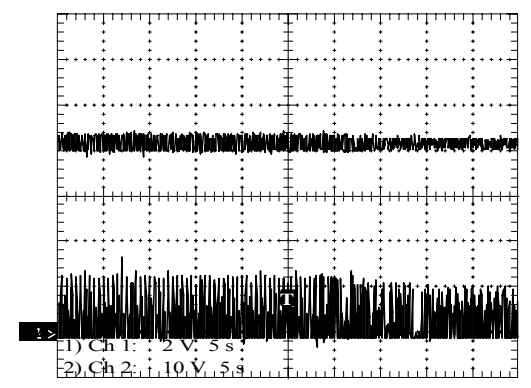

Fig. 36. Load voltage and current in the case of a speed transient (SRG controlled by VA strategy).

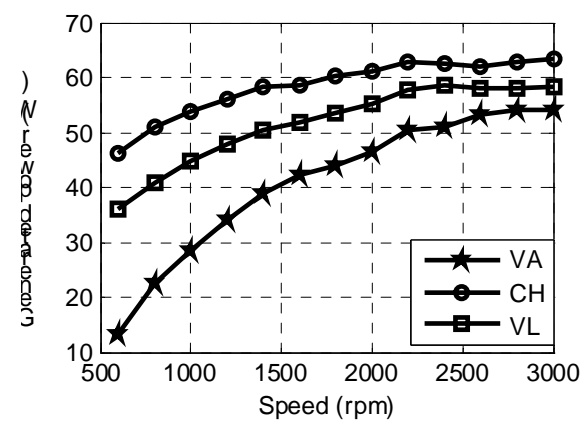

Fig. 37. Generated power (load resistance of $20 \Omega$ ).

\section{CONCLUSIONS}

In this paper, the operation of the SRM as a motor/generator is investigated. The results presented show that the SRM can be successfully used as motor/generator. There are several applications where this feature is desirable, as in automotive and aerospace applications and to storage mechanical energy in flywheels. The transition between motor and generator operation modes is verified. Three closed loop techniques to control the voltage delivered to the load are presented, simulated and fully digital implemented. The obtained results demonstrate that the control strategies have similar accuracy, although the one based on chopping the DC link during a fixed conduction angle presented the best electromechanical conversion capability. The VA strategy had the worst performance, being also less attractive because it requires accurate rotor position knowledge which in turn leads to higher costs. Any of the three control techniques presented can be easily implemented using a DSP or another low cost microcontroller and the designer can choose the more convenient strategy to attend the particularities of a specific embedded system. 


\section{ACKNOWLEDGEMENT}

The authors are grateful to $\mathrm{CNPq}$ and FAPEMIG for supporting the development of this work.

\section{REFERENCES}

[1] J. M. Miller, A.V. Rajarathnam, and M. Ehsani, "Current status and future trends in more electric car power systems" Proc. IEEE Vehicle Technology Conference, Houston, TX, May 1999.

[2] D. J. Perreault, "Automotive power generation and control". IEEE Transactions on Power Electronics, Vol. 19, no. 3, may 2004.

[3] B. Fahimi, et. al., "A switched reluctance machine-based starter/alternator for more electric cars" Transactions on Energy Conversion, Vol. 19, no. 1, March 2004.

[4] K. M. Rahman, B. Fahimi, et. al., "Advantages of switched reluctance motor applications to EV and HEV: Design and control issues" IEEE Transactions on Industry Appli., Vol. 36, pp. 119-121, Jan./ Feb. 2000.

[5] S. R. MacMinn and W. D. Jones, "A very high speed switched-reluctance starter-generator for aircraft engine applications" in Proc. IEEE Aerospace and Electron. Conf., Vol. 4, pp. 1758-1764, 1989.

[6] W. Cai, "Comparison and review of electric machines for integrated starter alternator applications", IEEE-IAS, 2004.

[7] P. Zhang, S. S. Williamson, "Recent status and future prospects of integrated starter-generator based hybrid electric vehicles" IEEE-VPPC, 2008.

[8] J. G. W. West, "DC, induction, reluctance and PM motors for electric vehicles" Power Engineering Journal, Vol. 8, Issue: 2, 1994.

[9] V. Nedic, T. A. Lipo, "Experimental verification of induced voltage self-excitation of a switched reluctance generator" IEEE-IAS, 2000.

[10] A. Martinez, et. al., "Use of an AC self-excited switched reluctance generator as a battery charger" 13th IEEEPEMC, 2008.

[11] A. Martinez, et. al., "Describing function analysis of the electric nonlinear model of a SRM autonomous AC generator" IEEE-PESC, 2008.

[12]N. Radimov, N. Ben-Hail, R. Rabinovici, "Switched reluctance machines as three-phase $\mathrm{AC}$ autonomous generators" IEEE Trans. on Magnetics, Vol. 43, $\mathrm{N}^{\circ} 11$, Nov. 2006

[13] R. Cárdenas, at. al., "Control of a switched reluctance generators for variable-speed wind energy applications" IEEE Trans. on Energy Conversion, Vol. 20, $\mathrm{N}^{\circ} 4$, Dec. 2005.

[14] K. W. E. Cheng, et. al. "Review of the wind energy generating systems" IEEE-APSCOM, 2009.

[15]R. de Andrade, G. G. Sotelo, A. C. Ferreira, L. G. B. Rolim, J. L. da Silva Neto, R. M. Stephan, W. I. Suemitsu, R. Nicolsky, "Flywheel energy storage system description and tests" Transactions on Applied Superconductivity, IEEE, Vol. 17, P. 2, 2007.

[16] P. Lawrenson, "Switched-reluctance motor drives" IEEE Electronics and Power, Vol. 29, Issue 2, 1983.
[17]A. V. S. Fleury, F. S. Silva; W. R. H. Araújo, D.A. Andrade, A. W. F. V. Silveira "Reduced switch count converter for switched reluctance generators" Eletrônica de Potência, Vol. 13, no. 3, Agosto 2008.

[18] M. Ehsani, B. Fahimi, "Elimination of position sensors in switched reluctance motor drives: State of the art and future trends" IEEE Transactions on Ind. Electronics, Vol. 49, pp. 40-48, Fev. 2002.

[19] Y. Chang, C. M. Liaw, "On the design of power circuit and control scheme for switched reluctance generator" Transactions on Power Electronics, vol. 23, no. 1, 2008.

[20] L. L. N. dos Reis, A. A. R. Coelho, O. M. Almeida, R. N. C. Almeida, "Modeling and control of switched reluctance motor drives based on set point relay" Eletrônica de Potência, Vol. 13, No.3., 2008.

[21] L. O. A. P. Henriques, L. G. B. Rolim, W. I. Suemitsu, P. J. C. Branco, "Uma revisão das estratégias de redução de ondulações de conjugado no motor de relutância chaveado" Eletrônica de Potência, Vol. 8, no. 1, 2003.

\section{BIOGRAPHIES}

Augusto Wohlgemuth Fleury Veloso da Silveira was born in Goiânia - Brazil, on August 27, 1981. He received the B. Sc. degree in computing engineering from Pontifícia Universidade Católica de Goiás (PUC-GO) and received his M. Sc. degree in electrical engineering from Universidade Federal de Uberlândia (UFU). $\mathrm{He}$ is currently working towards the Doctorate degree in electrical engineering at UFU. Presently he is a professor of the Department of Electrical Engineering of UFU, Brazil. His main areas of interest are electrical machines and drives.

Darizon Alves de Andrade was born in Monte Alegre de Minas - Brazil, on June 23, 1956. He received the B. Sc. and M. Sc. degrees from Universidade Federal de Uberlândia (UFU), Uberlândia, Brazil, and the Ph. D. degree from the University of Leeds, Leeds, U.K., in 1980, 1987, and 1994, respectively, all in electrical engineering. During the year 2000, he was a Visiting Scholar with the Motion Control Group, VTEC, Blacksburg, VA, USA, where he carried out research on new strategies for modeling SRMs. His teaching, research, and consulting interests are related to design, simulation, and control techniques associated with motion control of electromechanical energy converter devices and new developments in power quality. He has authored and coauthored several papers in these areas.

Luciano Coutinho Gomes was born in Barreira do Campo - Brazil, on October 20, 1972. He received the B. Sc,. M. Sc. and D. Sc. degrees from the Universidade Federal de Uberlândia (UFU), Uberlândia, Brazil, in 1995, 2002, and 2008, respectively, all in electrical engineering. In 2008, he joined the Faculdade de Engenharia Elétrica, UFU, where he is currently a Assistant Lecturer. His teaching, research, and consulting interests and activities are related to simulation and digital control techniques associated with motion control of electromechanical energy converter devices. He has authored and coauthored some papers in these areas. 
Carlos Augusto Bissochi Jr. received his B. Sc. degree in Electrical Engineering in 1994, from Universidade Estadual Paulista Júlio de Mesquisa Filho (UNESP). In 1997 and 2003, respectively, he received his M. Sc. and Ph. D. degrees, from Universidade Federal de Uberlândia (UFU). Presently, he is a professor of the Electrical Engineering Department of UFU, being involved with teaching and researching on systems automation, robotics, electric machine drives and control and also power electronics. His scientific and technological production includes AC/AC voltage regulators, switched audio amplifiers, symmetrical switched sources, EIE converters, new topologies, active load with energy recycling and electronic drive of electric machines.

Augusto Fleury Veloso da Silveira was born in Goiânia - Brazil, on August 30, 1953. He received the BSc. degree in physics and in electrical engineering both from the Universidade Federal de Goiás, Goiânia, Brazil, both in 1977. He also received the MSc degree in physics from the Universidade Federal de Goias, in 2001, and the Doctorate degree in electrical engineering from the Universidade Federal de Uberlândia, Brazil, in 2008. Nowadays he is going on ahead with researches on Switched Reluctance
Machines. From 1978 to 1985 , he was a Lecturer with the Pontifícia Universidade Católica de Goiás (PUC-GO). After this he was a Senior Consultant Engineer with the Engevix Engenharia S/C Ltda and later as a Senior Engineer with the Centrais Elétricas do Norte do Brasil S/A - Eletronorte. Presently he is with the Universidade Estadual de Goiás (UEG) and again with the PUC-GO, in both as a Senior Lecturer. His teaching, research, and consulting interests and activities are related to design, simulation, and control techniques associated with electrical machines and drives, and with alternative power sources. He has authored and coauthored papers published in these areas.

Hélder de Paula was born in Uberlândia - Brazil, on December 27, 1975. He received his B. Sc., M. Sc. and Ph. D. degrees in Electrial Engineering from Universidade Federal de Uberlândia, Brazil, in 1998, 2001 and 2005, respectively. In 2006, he joined the Electrical Engineering Department of Universidade Federal de Minas Gerais (UFMG), as a professor and member of the Industry Applications Laboratory. His main interests are motor drives, conducted electromagnetic compatibility, power quality and electromagnetic 